\title{
Transitivity processes in the field of higher medical education in the risk environment
}

\author{
Lyubov Khoronko ${ }^{1, *}$ and Yekaterina Bondarenko ${ }^{2}$ \\ ${ }^{1}$ Volgograd State Medical University, 400131, Volgograd, Russia \\ ${ }^{2}$ Don State Technical University, 344003, Rostov-on-Don, Russia
}

\begin{abstract}
The article deals with transitivity processes in the field of higher medical education. Several trends related to transitivity processes are highlighted: the high demand for medical education with a shortage of qualified specialists; the continuing medical education and the introduction of an accreditation exam; the introduction of distance technologies, simulation and e-learning; specialist mobility. Thus, the educational process in the context of transitivity processes in the field of medical education should be focused on the formation of self-improvement skills, selfeducation. The article describes the functions of the students' independent work in a medical university and the conditions that increase the effectiveness of the educational process. The article defines the role of the organization of student's independent work in the development of selfeducation and self-improvement skills. The student's independent work is considered as one of the forms that allow students to develop self-education and self-improvement skills, taking into account their abilities. The independent work as a form of self-improvement is aimed at developing the skills of independent search and choice of problem solutions; developing the skills of information analysis when working with a large volume of educational material; provides the development of critical thinking skills; stimulating the skills of evaluative and reflexive activity in the context of dynamic changes in the professional sphere.
\end{abstract}

\section{Introduction}

Today the phenomenon of transitivity is a characteristic feature of modern society. Transitivity is associated with the intensification of processes, the widespread use of hightech equipment, and the informatization of all spheres of human life.

The phenomenon of transitivity is characterized by the following features: irregularity and irreversible social processes that contribute to the development of new relationships; the high innovative activity. Innovation activity $[1,2]$ is a readiness to update the main elements of the innovation system - knowledge, technological equipment, information and communication technologies and conditions for their effective use. Innovations in the educational system [3, 4] are explained by the emergence of new Federal State Educational Standards (FSES). This is due to the introduction of new pedagogical technologies into the

\footnotetext{
*Corresponding author: kenho@mail.ru
} 
practice of the educational process, aimed at developing the student's personal qualities and abilities for self-development and self-education.

The changes in the field of higher education at the present stage are of a transitivity nature. These changes have also affected the medical education system. Knowledge of the mechanisms of changes occurring in the medical education system in Russia is important for understanding the impact of transitivity processes on the organization of the educational process in a medical university.

Transitivity processes in the medical education system of the Russian Federation are caused by the social demand for training highly qualified specialists in the medical education system. In medical education, transitivity processes are associated both with the modernization of professional education in general and with the systemic changes in the model of medical education itself.

\section{Materials and methods}

The problem of the deficiency of highly qualified personnel in the field of medicine is currently at center stage. This is due to the state of the medical education system, in which we will highlight the following potential risks:

- in the organization of the educational process, there is no clear direction for the formation of readiness of medical students for professional activity in transitivity conditions, taking into account the trends in the development of the world and domestic medicine;

- there is a lag between the pace of modernization of the system of medical personnel training and the need for specialists who can perform their professional duties efficiently and strive for self-improvement, self-education, and professional development.

The risks mentioned above indicate the need to identify new strategic guidelines in the system of training medical personnel. At the same time, it is necessary to take into account several trends that have the greatest impact on the transitivity processes of modern medical education:

1. The first trend is a High Demand for Medical Education with a Deficiency of Doctors. In modern conditions, there is a deficiency of personnel in certain medical specialties (the lack of anesthesiologists-resuscitators, pathologists, morphologists, infectious diseases specialists, epidemiologists). The training of students at a medical university must meet the dynamic requirements occurring in the world and Russia.

2. The second trend is Continuing Medical Education (CME). CME is the development of professional knowledge and skills throughout life, continuous improvement of professional level and expanding of professional competence - "life-long learning". The principles of the continuing system of medical education are individuality, continuity, cooperation with professional medical and pharmaceutical organizations, wide use of distance learning technologies [5, 6], simulation and e-learning [7, 8].

3. Implementing the Accreditation Exam - a comprehensive test of knowledge, practical skills and clinical thinking $[9,10]$.

The accreditation exam is taken upon completing the training at a medical university and the Examination Committee consists not of instructors, but potential employers, doctors of medical institutions. This practice helps to improve the quality of students' training.

In 2017, 97.9\% of graduates in all specialties of the Healthcare and Medicine group successfully passed the Accreditation Exam. By 2021, all medical professionals with higher and secondary professional education will be involved in the Accreditation System.

I.A. Kassirskiy, a well-known scientist and clinician, pointed out that in areas such as medicine and biology, scientists have problems with the observational analysis of pathological phenomena. Scientists make incorrect diagnoses because they cannot think logically. 
The process for accreditation of a specialist is a procedure for determining whether a university graduate or current specialist is ready to "carry out medical activities in a particular medical specialty by the professional standard for the specialty" [11]. According to the requirements documents regulating the accreditation process, the accreditation of a specialist is carried out in several stages. At the first stage, within the framework of primary accreditation, testing is conducted, and the practical skills of a specialist in the conditions of using simulators, mannequins, and solving clinical cases are evaluated. With periodic accreditation, the portfolio is evaluated and tested. At the third stage of accreditation, the graduate/specialist solves three situational tasks in the form of case studies, within the framework of which the subject is asked to solve the situation of professional activity in real conditions, reflecting the practical problem and the possession of professional competencies. 4. Interdisciplinary Approach. Introduction of interdisciplinary specializations in the educational process, which will allow forming unique competencies [12].

5. Digital Technologies in Medicine. The use of a computer, on-line technologies and distance learning in modern higher education is becoming a priority in the organization of the educational process. The introduction of distance learning makes it more accessible by place, time, and pace of learning (individual educational trajectory) [13]. Distance learning is widely used in the system of Continuing Medical Education (CME), up to 30\% of the time is devoted to the so-called "self-education". Distance learning is a form of organizing independent work within the framework of medical education of students and advanced training courses for doctors $[14,15]$.

6. The Increasing Mobility of Medical Professionals. The role of this trend has increased with the spread of the new COVID-19 coronavirus infection in 2020. Employees of all medical specialties in the conditions of the pandemic must have broad knowledge and skills: from general therapeutic, general medical training to knowledge in the field of narrow specialization, skills to assess the severity of the patient's condition, communication skills, stress resistance in conditions of intensive work.

Based on the facts mentioned above, we will highlight the current direction in the training of medical personnel. Currently, the educational policy upon the conditions of transitivity processes in the field of medical education should be focused on the formation of selfimprovement skills and self-education.

The key task of medical professional education is to ensure that the student not only receives medical knowledge but also to form independent activity skills that allow him to improve throughout life, "life-long learning".

\section{Results and discussion}

The issues of organization and planning of students' independent work in the course of training were analyzed by O.I. Vaganova [16], E.M. Ibragimova [17], I.A. Pogrebnaya [18], V.V. Sadovaya [19], and other foreign researchers [20]. After analyzing these authors' works, we can conclude that the students' independent work is a form of organization of the educational process, which is carried out under the supervision of a teacher, while students with varying degrees of self-dependence perform tasks to develop knowledge, skills, and personal qualities.

In the studies of professional training of medical university students devoted to the study of the organization of independent work, the authors propose the independent work as a "planned activity", in which tasks are performed under the supervision of a teacher; as an active form of extracurricular students' work aimed at increasing their activity and independence and acting as the basis for self-education [16]. The independent work is defined as a form of improving self-educational competence - the key competence of the ThirdGeneration Educational Standard. This approach to organizing the students' independent 
work, where the supervision teacher's function is efficient. On the one side, this is determined by a wide range of educational and professional tasks that are solved in the process of independent work, on the other side, this is due to the lack of self-education skills among medical students at the initial stages of training.

O.Yu. Polyanichko proves in her work the importance and necessity of forming selfeducational competence and offers a model of independent work, where the main goal is the formation of self-education competence. Self-education is a process of personal development that occurs gradually.

Usually, independent work is divided into types: educational, scientific and social, according to the methods of organization, control, methodological support, etc. The form of students' independent work used in the learning process at the university may vary depending on the objectives of training, specifics of the studied subjects, volume, and the time needed to study the material.

Independent work of medical students being performed during the course of studies includes the activity in the form of educational discussions, solving situational tasks.

The analysis of the studies allowed determining that independent work performs stimulating, organizational, research, development, orientation and regulatory functions.

Independent work in the preparation of students performs the following didactic functions:

- stimulating function - the students' motivation aimed at independent search and choice of solutions to the task;

- developmental function: development of information analysis skills when working with a large amount of educational material;

- research function which provides the development of critical thinking skills;

- organizational function: the development of self-education skills, stimulation of cognitive activity skills in solving professional tasks;

- regulatory function: stimulating the skills of evaluative and reflexive activity in the context of dynamic changes in the professional sphere.

The independent work at the university increases the effectiveness of the educational process due to the organization of:

- conditions for the forming skills of self-organization, self-analysis and self-control;

- various forms to learn the material for accumulating personal experience (value experience, reflection experience);

- factors allowing to master professional competencies for solving standard tasks;

- stable attitude for accumulating professional knowledge and skills;

- options providing the formation of the ability to learn independently throughout life, "life-long learning".

\section{Conclusion}

Thus, the effective organization of independent work of medical university students will reduce the risks associated with transitivity processes in the field of medical education. At the same time, it is necessary to use the principle of systematic expansion of knowledge when studying the material aimed at the independent search for information, systematization and classification, critical analysis, and search for possible errors in solving professional tasks.

The independent work organized at a medical university includes working on individual parts within the studied subject; performing tasks at the laboratory and practical classes; preparing for intermediate and final certification; taking practical training and completing tasks within the framework of the practice report. When solving professional tasks within the framework of organizing independent work of a student, theoretical knowledge is formed, as well as the development of practical skills, skills of cognitive activity and critical thinking, 
skills of evaluative and reflexive activity. The independent work at the university is a form of preparation of medical students for professional activity in the risks environment.

\section{References}

1. A. Simacheva, O. Krasnoryadtseva, T. Vaulina, E. Shcheglova, Procedia - Social and Behavioral Sciences 237, 1366-1370 (2017)

2. I. Dougherty, A. Clarke, Emerging Adulthood 6(5), 358-365 (2018) https://doi.org/10.1177/2167696817739393

3. R. Locke, et al., Health Professions Education (2020) doi.org/10.1016/j.hpe.2020.08.002

4. M.A.R. López, Procedia - Social and Behavioral Sciences 237, 1505-1512 (2017) doi.org/10.1016/j.sbspro.2017.02.237

5. O.T. Arulogun, O.N. Akande, A.T. Akindele, T.A. Badmus, Data in Brief 31, 105929 (2020)

6. K.T. Arnesen, J. Hveem, C.R. Short, R.E. West, M.K. Barbour, Distance Educ. 40(1), 32-53 (2019)

7. A.R. Smith, C. Cavanaugh, W.A. Moore, BMC Med Education 11, 38 (2011) https://doi.org/10.1186/1472-6920-11-38

8. Sook Jung Kang, Chong Min Hong, and Hyerim Lee, Clinical Simulation in Nursing (2020) https://doi.org/10.1016/j.ecns.2020.05.008

9. V. Papalois, Cirugía Española 95.3, 131-134 https://doi.org/10.1016/j.cireng.2017.04.011

10. M.E. Ray, L. Du Brava, M. Jacks, Currents in Pharmacy Teaching and Learning (2020) https://doi.org/10.1016/j.cptl.2020.07.004

11. B. Jibril, O. Houache, Procedia - Social and Behavioral Sciences 102, 352-360 (2013) https://doi.org/10.1016/j.sbspro.2013.10.750

12. P. Kukko, M. Silén-Lipponen, T. Saaranen, Nurse Education Today (2020)

13. Z.M. Sizova, V.N. Tregubov, T.N. Malakhova, Stomatologiia 96.2, 66-69 (2017)

14. T. Surma, P.A. Kirschner, Computers in Human Behavior 110 (2020)

15. L.B. Rakototiana, S. Rajabo Gottot, BMC Med Educ 17, 152 (2017) https://doi.org/10.1186/s12909-017-0991-3

16. O.I. Vaganova, et al., Amazonia Investiga 9.27, 376-382 (2020)

17. E.M. Ibragimova, International Journal of Educational Sciences 27, 1-6 (2019) DOI: $10.31901 / 24566322.2019 / 27.1-3.1092$.

18. I.A. Pogrebnaya, S.V. Mikhailova, L.A. Ibragimova, Amazonia investiga 8.21, 483-490 (2019)

19. V.V. Sadovaya, A.O. Luchinina, A.A. Reznikov, International Electronic Journal of Mathematics Education 11.1, 327-337 (2016)

20. K. Premkumar, E. Vinod, S. Sathishkumar, et al., BMC Med Educ 18, 134 (2018) https://doi.org/10.1186/s12909-018-1244-9 